\title{
Treatment Persistence and Healthcare Costs Among Patients with Rheumatoid Arthritis Changing Biologics in the USA
}

\author{
Benjamin Chastek (D) Chieh-I Chen · Clare Proudfoot • \\ Shraddha Shinde $\cdot$ Andreas Kuznik $\cdot$ Wenhui Wei
}

Received: July 19, 2017 / Published online: October 16, 2017

(C) The Author(s) 2017. This article is an open access publication

\begin{abstract}
Introduction: After a patient with rheumatoid arthritis (RA) fails tumor necrosis factor inhibitor (TNFi) treatment, clinical guidelines support either cycling to another TNFi or switching to a different mechanism of action (MOA), but payers often require TNFi cycling before they reimburse switching MOA. This study examined treatment persistence, cost, and cost per persistent patient among MOA switchers versus TNFi cyclers.

Methods: This study of Commercial and Medicare Advantage claims data from the Optum Research Database included patients with RA and
\end{abstract}

Enhanced content To view enhanced content for this article go to http://www.medengine.com/Redeem/ 8E1CF0603475BBAC.

B. Chastek $(\square)$

Optum, Eden Prairie, MN, USA

e-mail: benjamin.chastek@optum.com

C-I. Chen · A. Kuznik

Regeneron Pharmaceuticals, Inc, Tarrytown, NY, USA

S. Shinde $\cdot$ W. Wei

Formerly of Sanofi, Bridgewater, NJ, USA

C. Proudfoot

Formerly of Sanofi, Guildford, UK

Present Address:

W. Wei

Regeneron Pharmaceuticals, Inc, Tarrytown, NY, USA at least one claim for a TNFi (adalimumab, certolizumab pegol, etanercept, golimumab, or infliximab) between January 2012 and September 2015 who changed to another TNFi or a different MOA therapy (abatacept, tocilizumab, or tofacitinib) within 1 year. The index date was the date of the change in therapy. Treatment persistence was defined as no subsequent switch or 60-day gap in therapy for 1 year post-index. RA-related costs included plan-paid and patient-paid amounts for inpatient, outpatient, and pharmacy claims. Medication costs included index and post-index costs of TNFi and different MOA therapies.

Results: There were 581 (38.3\%) MOA switchers and 935 (61.7\%) TNFi cyclers. The treatment persistence rate was significantly higher for MOA switchers versus TNFi cyclers $(47.7 \%$ versus $40.2 \%, P=0.004)$. Mean 1-year healthcare costs were significantly lower among MOA switchers versus TNFi cyclers for total RA-related costs $(\$ 37,804$ versus $\$ 42,116 ; P<0.001)$ and medication costs $(\$ 29,001$ versus $\$ 34,917 ; P<0.001)$. When costs were divided by treatment persistence, costs per persistent patient were lower among MOA switchers versus TNFi cyclers: $\$ 25,436$ lower total RA-related cost and $\$ 25,999$ lower medication costs.

Conclusion: MOA switching is associated with higher treatment persistence and lower healthcare costs than TNFi cycling. Reimbursement policies that require patients to cycle TNFi before switching MOA may result in suboptimal outcomes for both patients and payers. 
Funding: Sanofi and Regeneron Pharmaceuticals.

Keywords: bDMARD; Biological diseasemodifying antirheumatic drugs; Cost; Persistence; Rheumatoid arthritis; Rheumatology; Switching; TNFi; Tumor necrosis factor inhibitor

\section{INTRODUCTION}

Rheumatoid arthritis (RA) is a chronic inflammatory disease that is characterized by synovitis (i.e., joint swelling) in at least one joint without an alternative etiology [1]. Treatment guidelines for RA recommend initiating treatment with a conventional synthetic disease-modifying antirheumatic drug (DMARD) such as methotrexate [2-4]. Previously, if disease activity remained moderate or high despite DMARD monotherapy, the recommendation was to switch to combination DMARD therapy or treatment with a tumor necrosis factor inhibitor (TNFi). If the initial TNFi was ineffective or poorly tolerated, patients could either switch to a different mechanism of action (MOA) or cycle to another TNFi. Recent updates to RA treatment guidelines recommend the use of different MOA therapies earlier in the treatment paradigm $[5,6]$. Other MOA therapies now are recommended either as an alternative option to a TNFi for first-line biological therapy [5] or as an option for second-line therapy after a TNFi instead of cycling to another TNFi [6].

The changes to the treatment guidelines are supported by emerging evidence of better treatment persistence, clinical outcomes, and lower costs with a different MOA compared with a TNFi. Recent analyses have reported that treatment persistence is better after switching to a different MOA compared with TNFi cycling [7-10]. Emerging data from clinical studies show that outcomes also favor MOA switching over TNFi cycling. A randomized, open-label study of 300 patients with RA and an insufficient response to a TNFi reported that MOA switchers had approximately twice the odds of TNFi cyclers to achieve a good or moderate European League Against Rheumatism (EULAR) response
24 weeks after the change in therapy (odds ratio 2.06; 95\% confidence interval [CI] 1.27-3.37; $P=0.004)$ [11]. A different MOA therapy also may be a more cost-effective choice, being both more effective and less expensive than a TNFi in the treatment of RA [12].

Despite the evidence to support switching to a different MOA, TNFi cycling is more common than MOA switching in clinical practice [7-10, 13-20]. A likely contributor to the greater frequency of TNFi cycling across populations and across studies is that as a result of contracting and manufacturer rebates, many payers require a patient to cycle TNFi before the patient can access a different MOA [21]. Another possible contributor was the availability of TNFi before different MOA therapies, leading to greater physician familiarity and comfort with TNFi therapy.

In clinical practice, poor treatment persistence (i.e., discontinuation of therapy) and poor treatment adherence (i.e., using a therapy less often than as prescribed) may undermine the intended effects of therapies for RA, thereby contributing to ineffective treatment [22]. Poor treatment persistence after dispensing a medication for RA also may lead to costly medication expenditures for unused medications. The objective of this study was to examine cost per persistent patient with RA after switching from a TNFi to a different MOA versus cycling to another TNFi.

\section{METHODS}

\section{Study Design}

This retrospective study used both Commercial claims data and Medicare Advantage claims data from the Optum Research Database. All records were de-identified and no identifiable protected health information was extracted or accessed during the study, pursuant to the US Health Insurance Portability and Accountability Act. Because the study did not involve the collection, use, or transmittal of individually identifiable data, and data were collected in the setting for the usual care of the patient, institutional review board approval to conduct this study was not necessary. 


\section{Patients}

The study included patients who were continuously enrolled in either a commercial health plan or a Medicare Advantage health plan with both a medical and pharmacy benefit. All patients had at least one claim for a TNFi (adalimumab, certolizumab pegol, etanercept, golimumab, or infliximab) between January 1 , 2012, and September 30, 2015. The analysis was designed to examine a change in therapy regardless of how long the prior TNFi was used. Thus, the patient's first lifetime use of the TNFi could occur before the first TNFi claim in this period. Analyzed patients were continuously enrolled for at least 6 months before and at least 12 months after the first TNFi claim, were at least 18 years of age as of the first TNFi claim, and had a diagnosis of RA (ICD-9: 714.0x) in the primary or secondary position in the 6 months before or 30 days after the first TNFi claim.

During the 1-year period after the first TNFi claim, patients changed therapy to a different targeted DMARD, either by cycling to another TNFi or by switching to a different MOA therapy (abatacept, tocilizumab, or tofacitinib). The date of the switch to a different targeted DMARD during this period was considered the index date for TNFi cycling or MOA switching. After the change in therapy on the index date, patients were required to be continuously enrolled in a Commercial or Medicare Advantage health plan with medical and pharmacy benefit for at least 12 months to allow for examination of outcomes and costs for 1 year post-index. Patients were allowed to have a variable length follow-up of at least 1 year, ending with the earlier of disenrollment from the health plan or September 30, 2015.

Patients were excluded from the study if they were diagnosed with another autoimmune condition (Crohn's disease, ulcerative colitis, ankylosing spondylitis, psoriasis, psoriatic arthritis, or juvenile idiopathic arthritis). Study variables were evaluated for two cohorts of biologic switchers: TNFi cyclers, who received a TNFi pre-index and a different TNFi at index; and MOA switchers, who received a TNFi pre-index and a different MOA therapy at index.

\section{Outcomes}

Duration of treatment persistence was examined over the variable length follow-up up to 2 years and during the first 12 months of follow-up. Treatment patterns were determined during the first 12 months post-index for each patient. Persistence with the index treatment was measured as days to therapy discontinuation or switching. Discontinuation of the index treatment was defined as an observed gap in therapy of at least 60 days following the runout date of a fill/infusion.

Total RA-related costs of diagnosis and treatment in the 1-year post-index period were based on paid amounts of adjudicated claims (inpatient, outpatient, and pharmacy), using the sum of plan-paid and patient-paid amounts. Costs were attributed to RA for a non-diagnostic medical claim with a RA diagnosis in any position or a hospitalization with a diagnosis of RA in any position at any time during the stay. RA-related medications included both targeted DMARDs (TNFi or different MOA) and conventional DMARDs (hydroxychloroquine, leflunomide, methotrexate, or sulfasalazine). Separate analyses were conducted for cost of claims paid for all targeted DMARDs in the 1-year post-index period. The cost of targeted DMARDs was adjusted to account for inflation using a biologic-specific inflation factor. The cost of all other services was adjusted for inflation using the medical component of the Consumer Price Index. To derive the cost per persistent patient over 1 year, costs in the 1-year post-index period were divided by the total number of patients who were persistent for 1 year after TNFi cycling or MOA switching.

\section{Statistical Analysis}

For each analysis, results were stratified by study cohort (TNFi cyclers or MOA switchers) and $P$ values were calculated to compare the cohorts. Chi square tests were performed for categorical measures and ANOVA was utilized for continuous measures. Kaplan-Meier analyses were conducted for persistence during the variable length follow-up with estimates provided at 
Table 1 Patient demographics

\begin{tabular}{|c|c|c|c|c|}
\hline & $\begin{array}{l}\text { Total } \\
(N=1516)\end{array}$ & $\begin{array}{l}\text { MOA switchers } \\
(N=581)\end{array}$ & $\begin{array}{l}\text { TNFi cyclers } \\
(N=935)\end{array}$ & $\begin{array}{l}P \text { value: MOA } \\
\text { switchers versus } \\
\text { TNFi cyclers }\end{array}$ \\
\hline Age, years, mean (SD) & $52.5(11.3)$ & $53.6(11.2)$ & $51.9(11.3)$ & 0.005 \\
\hline \multicolumn{5}{|l|}{ Gender, $n(\%)$} \\
\hline Male & $297(19.6)$ & $100(17.2)$ & $197(21.1)$ & 0.066 \\
\hline Female & $1219(80.4)$ & $481(82.8)$ & $738(78.9)$ & 0.066 \\
\hline \multicolumn{5}{|l|}{ Insurance, $n(\%)$} \\
\hline Commercial & $1273(84.0)$ & $475(81.2)$ & $798(85.4)$ & 0.064 \\
\hline Medicare & $243(16.0)$ & $106(18.2)$ & $137(14.7)$ & 0.064 \\
\hline \multicolumn{5}{|c|}{ Number of targeted DMARDs received ${ }^{\mathrm{a}}$} \\
\hline$n$ & 1516 & 581 & 935 & \\
\hline Mean (SD) & $0.87(0.84)$ & $1.07(1.0)$ & $0.75(0.70)$ & $<0.001$ \\
\hline 0 & $520(34.3)$ & $169(29.1)$ & $351(37.5)$ & $<0.001$ \\
\hline 1 & $755(49.8)$ & $267(46.0)$ & $488(52.2)$ & 0.018 \\
\hline $2+$ & $241(15.9)$ & $145(25.0)$ & $96(10.3)$ & $<0.001$ \\
\hline
\end{tabular}

Days from earliest biologic to index, $n(\%)^{\mathrm{a}}$

$\begin{array}{lllll}n & 996 & 412 & 584 & \\ \text { Mean (SD) } & 681.44(694.2) & 727.55(711.9) & 648.91(680.2) & 0.078 \\ <180 \text { days } & 310(20.5) & 115(19.8) & 195(20.9) & 0.618 \\ 180 \text { to }<360 \text { days } & 209(13.8) & 83(14.3) & 126(13.5) & 0.657 \\ 360 \text { to }<540 \text { days } & 68(4.5) & 37(6.4) & 31(3.3) & 0.005 \\ 540 \text { to }<720 \text { days } & 63(4.2) & 27(4.7) & 36(3.9) & 0.450 \\ >720 \text { days } & 346(22.8) & 150(25.8) & 196(21.0) & 0.029\end{array}$

Days from earliest RA claim (diagnosis or treatment), $n(\%)^{\mathrm{a}}$

\begin{tabular}{|c|c|c|c|c|}
\hline$n$ & 1515 & 581 & 934 & \\
\hline Mean (SD) & $750.9(719.7)$ & $815.2(733.2)$ & $710.8(708.6)$ & 0.006 \\
\hline$<180$ days & $296(19.5)$ & $100(17.2)$ & $196(21.0)$ & 0.073 \\
\hline 180 to $<360$ days & $414(27.3)$ & $148(25.5)$ & $266(28.5)$ & 0.206 \\
\hline 360 to $<540$ days & $137(9.0)$ & $49(8.4)$ & $88(9.4)$ & 0.518 \\
\hline 540 to $<720$ days & $100(6.6)$ & $43(7.4)$ & $57(6.1)$ & 0.320 \\
\hline $720+$ days & $568(37.5)$ & $241(41.5)$ & $327(35.0)$ & 0.011 \\
\hline
\end{tabular}

$D M A R D$ disease-modifying antirheumatic drug, $M O A$ mechanism of action, $R A$ rheumatoid arthritis, $S D$ standard deviation, TNFi tumor necrosis factor inhibitor

a Based on a variable pre-index period with all available data; missing data were not included in the count 
discrete intervals through the first 2 years of follow-up. Median persistence with 95\% CI was determined from the Kaplan-Meier analysis. The number and percentage of patients who were persistent with the index therapy at 1 year was identified and used in the calculation of cost per persistent patient. Total RA-related costs and targeted DMARD costs in the 1-year post-index period were analyzed descriptively. To control for baseline differences between the TNFi cyclers and MOA switchers, multivariable analyses were conducted to examine 1-year persistence (logistic), follow-up RA-related healthcare cost (generalized linear model [GLM]), and follow-up cost of targeted DMARDs (GLM). Covariates for each model included cohort (TNFi cycling versus MOA switching), age group (18-44 or 45-64, versus $65+$ ), gender, commercial insurance versus Medicare Advantage, index year, region, an aggregate score for comorbid conditions (Charlson comorbidity index $[23,24])$, use of DMARDs during baseline, count of RA medications in a variable length baseline, total baseline cost, total baseline RA-related cost, and count of baseline office visits.

\section{RESULTS}

\section{Study Population}

The study population of 1516 patients included 581 (38.3\%) MOA switchers and 935 (61.7\%) TNFi cyclers (Table 1). Mean age at the index date (the date of MOA switching or TNFi cycling) was 52.5 years, most patients $(80.4 \%)$ were female. Most patients $(84.0 \%)$ were commercially insured; the other $16.0 \%$ were insured by Medicare Advantage. Differences were observed between the cohorts for demographics and prior therapy, including the mean number of targeted DMARDs received any time pre-index (1.07 for MOA switchers and 0.75 for TNFi cyclers; $P<0.001$ ) or the mean time from the first TNFi claim to the index date (727.6 versus 648.9 days, respectively; $P=0.078$ ).

\section{Treatment Persistence}

From the Kaplan-Meier analysis, median treatment persistence over the variable length follow-up after the change in therapy on the index

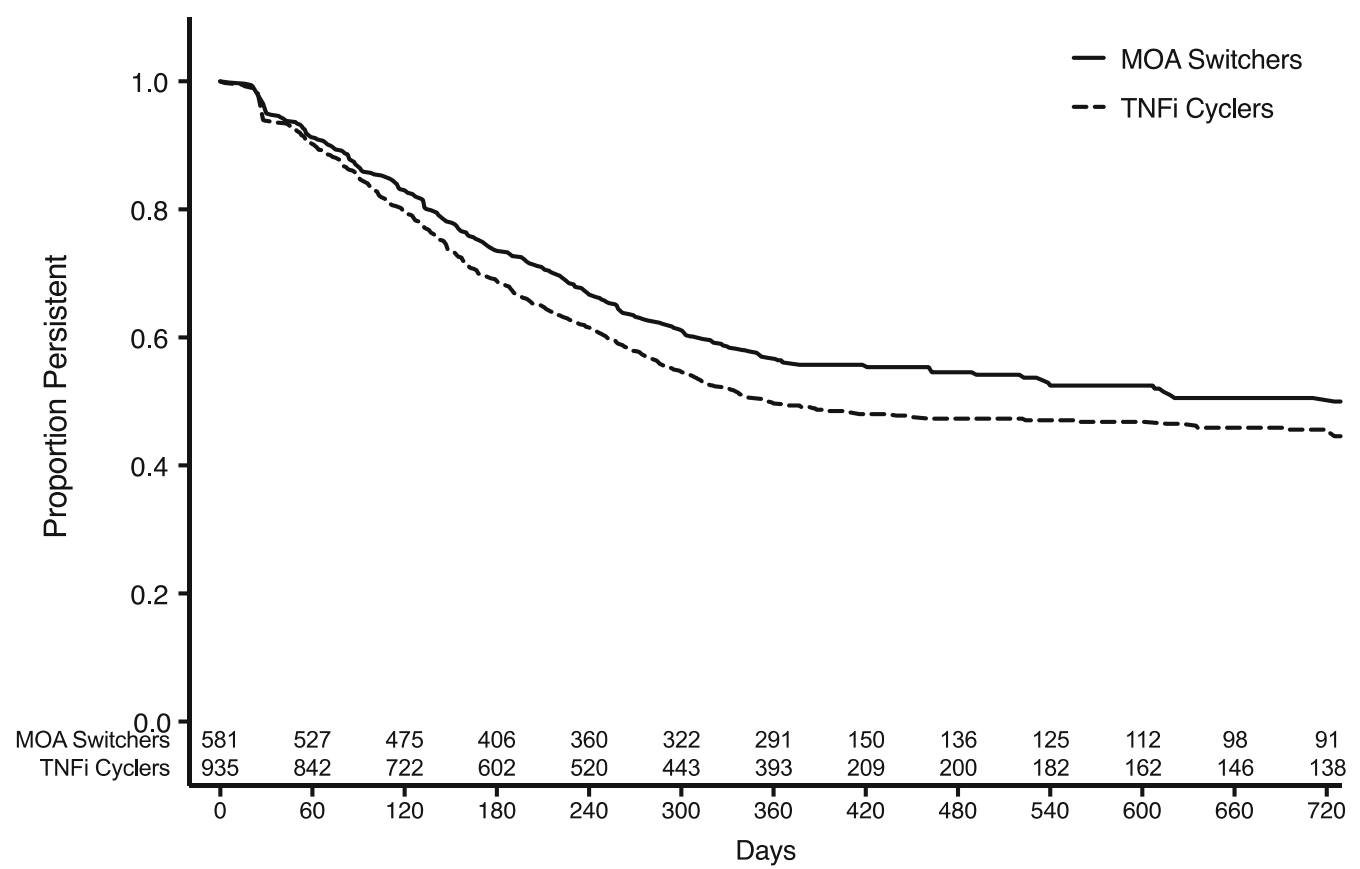

Fig. 1 Kaplan-Meier plot for treatment persistence after cycling to another tumor necrosis factor inhibitor (TNFi cycling) or switching from a TNFi to a different mechanism of action (MOA) 
date was 366 days (95\% CI 311-618) for MOA switchers and 279 days (95\% CI 257-306) for TNFi cyclers (Fig. 1). The 1-year treatment persistence rate was $47.7 \%$ for MOA switchers and $40.2 \%$ for TNFi cyclers $(P=0.004)$ (Fig. 2). Significant differences between MOA switchers and TNFi cyclers also were observed for switching (29.6\% versus $39.6 \% ; P<0.001)$ and restarting after a 60-day treatment gap $(10.2 \%$ versus $6.8 \% ; \quad P=0.022)$. A similar proportion of patients-approximately $13 \%$ in each cohortdiscontinued targeted DMARD therapy (i.e., had a treatment gap of at least 60 days without a subsequent restart).

In the multivariable analysis that included treatment cohort and baseline patient characteristics as covariates (Table 2), TNFi cyclers had significantly lower odds of treatment persistence at 1 year than MOA switchers $(\mathrm{OR}=0.72$; $95 \%$ CI $0.58-0.89 ; P=0.003)$. Other statistically significant predictors of 1-year persistence post-index in the multivariable analysis were geographic region (Midwest versus South), comorbidity index score, total expenditure pre-index, and RA-related total expenditure pre-index.

\section{Cost}

The mean costs for 1-year post-index were significantly lower among MOA switchers versus TNFi cyclers, including \$4311 lower total RA-related costs $(\$ 37,804$ versus $\$ 42,116$; $P<0.001)$ and $\$ 5916$ lower targeted DMARD costs $(\$ 29,001$ versus $\$ 34,917 ; \quad P<0.001)$ (Fig. 3a). In each cohort, the health plan paid 93-95\% of the costs and the patient paid $5-7 \%$ of the costs. In the multivariable analyses that included treatment cohort and baseline patient characteristics as covariates, MOA switchers had significantly lower costs than TNFi cyclers at 1 year for RA-related costs (cost ratio $=0.89 ; \quad 95 \% \quad$ CI $\quad 0.84-0.94$; $P<0.001$ ) (Table 3) and targeted DMARD costs (cost ratio $=0.84 ; \quad 95 \% \quad$ CI $\quad 0.79-0.88$; $P<0.001$ ) (Table 4). Other statistically significant predictors of 1-year post-index costs in the multivariable analyses included age 4564 years (compared with age $65+$ years), total pre-index expenditures, and office visit count pre-index.

When costs were divided by the treatment persistence rates, the estimated costs per

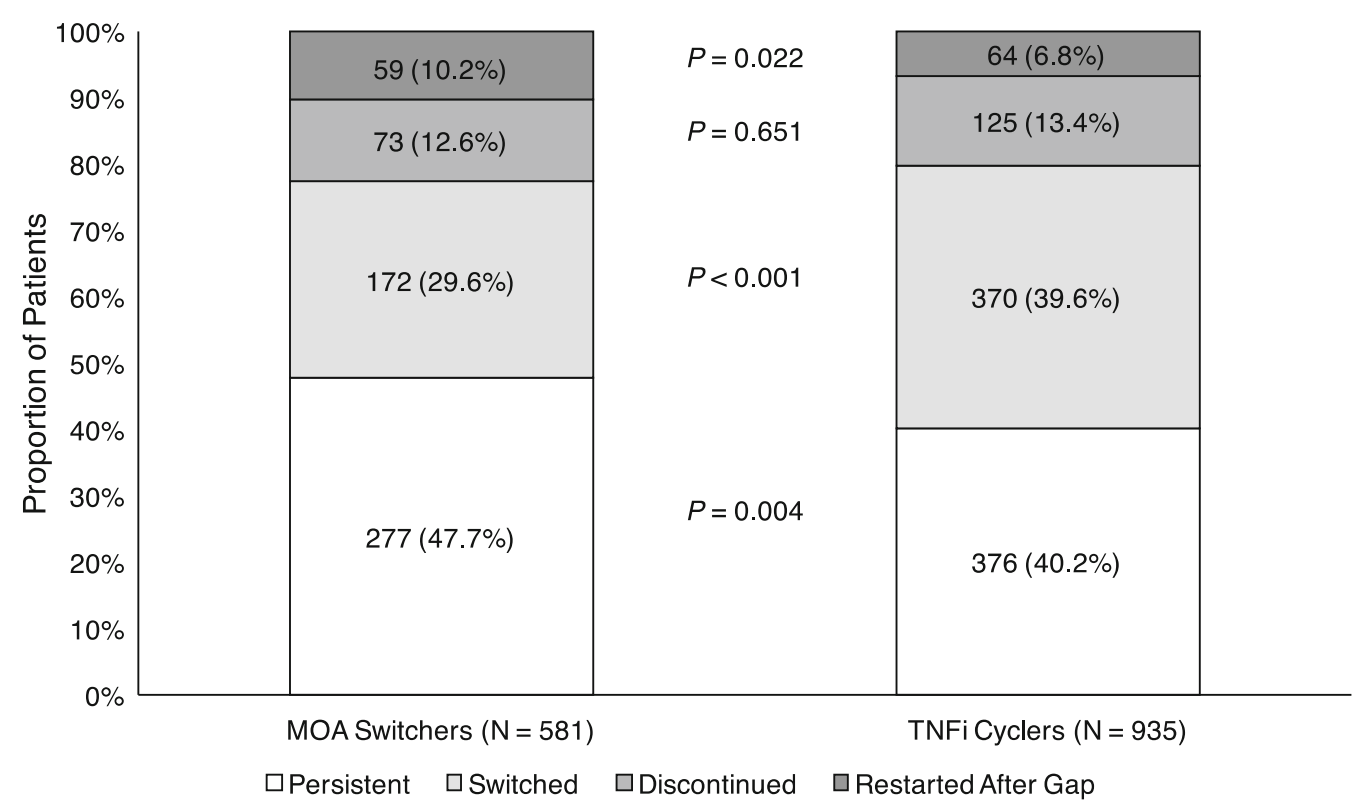

Fig. 2 Treatment patterns during the 1-year post-index period. MOA mechanism of action, TNF $i$ tumor necrosis factor inhibitor 
Table 2 Multivariable analysis of predictors for 1-year persistence

\begin{tabular}{|c|c|c|c|c|}
\hline & Odds ratio & Lower 95\% CI & Upper $95 \% \mathrm{CI}$ & $P$ value \\
\hline \multicolumn{5}{|l|}{ Patient cohort (ref = MOA switchers) } \\
\hline TNFi cyclers & 0.717 & 0.576 & 0.894 & 0.003 \\
\hline \multicolumn{5}{|l|}{ Age group $(\mathrm{ref}=65+)$} \\
\hline $18-44$ & 0.660 & 0.435 & 1.001 & 0.050 \\
\hline $45-64$ & 0.812 & 0.565 & 1.167 & 0.260 \\
\hline Male $(\mathrm{ref}=$ female $)$ & 1.134 & 0.871 & 1.477 & 0.350 \\
\hline \multicolumn{5}{|l|}{ Insurance plan type $(\mathrm{ref}=$ commercial $)$} \\
\hline Medicare & 1.278 & 0.912 & 1.790 & 0.154 \\
\hline \multicolumn{5}{|l|}{ Index year $(\mathrm{ref}=2012)$} \\
\hline 2013 & 0.891 & 0.684 & 1.161 & 0.394 \\
\hline 2014 & 0.773 & 0.510 & 1.173 & 0.226 \\
\hline \multicolumn{5}{|l|}{ Region (ref $=$ South) } \\
\hline Northeast & 1.310 & 0.876 & 1.960 & 0.189 \\
\hline Midwest & 1.371 & 1.067 & 1.762 & 0.014 \\
\hline West & 1.116 & 0.825 & 1.510 & 0.477 \\
\hline Charlson comorbidity index & 0.854 & 0.741 & 0.984 & 0.029 \\
\hline Hydroxychloroquine pre-index & 1.014 & 0.775 & 1.325 & 0.922 \\
\hline Leflunomide pre-index & 0.918 & 0.663 & 1.269 & 0.603 \\
\hline Methotrexate pre-index & 1.137 & 0.914 & 1.414 & 0.250 \\
\hline Sulfasalazine pre-index & 1.171 & 0.785 & 1.745 & 0.439 \\
\hline Count of unique RA medications pre-index & 0.971 & 0.839 & 1.125 & 0.698 \\
\hline Total expenditure pre-index $/ \$ 1000$ & 0.981 & 0.964 & 0.998 & 0.027 \\
\hline RA-related total expenditure pre-index $/ \$ 1000$ & 1.027 & 1.010 & 1.045 & 0.002 \\
\hline Office visit count pre-index & 0.997 & 0.980 & 1.014 & 0.703 \\
\hline Patient paid amount for index claim & 1.000 & 1.000 & 1.000 & 0.684 \\
\hline
\end{tabular}

$M O A$ mechanism of action, $R A$ rheumatoid arthritis, ref reference, $T N F i$ tumor necrosis factor inhibitor

persistent patient over the 1-year follow-up period were lower among MOA switchers versus TNFi cyclers, including \$25,436 lower total RA-related cost per persistent patient and $\$ 25,999$ lower targeted DMARD costs per persistent patient (Fig. 3b).

\section{DISCUSSION}

In this real-world study of more than 1500 patients with RA who received a TNFi and then required a switch in therapy, MOA switchers had a longer treatment duration than TNFi 
(A) Mean (SD) costs per patient in 1-year follow-up period

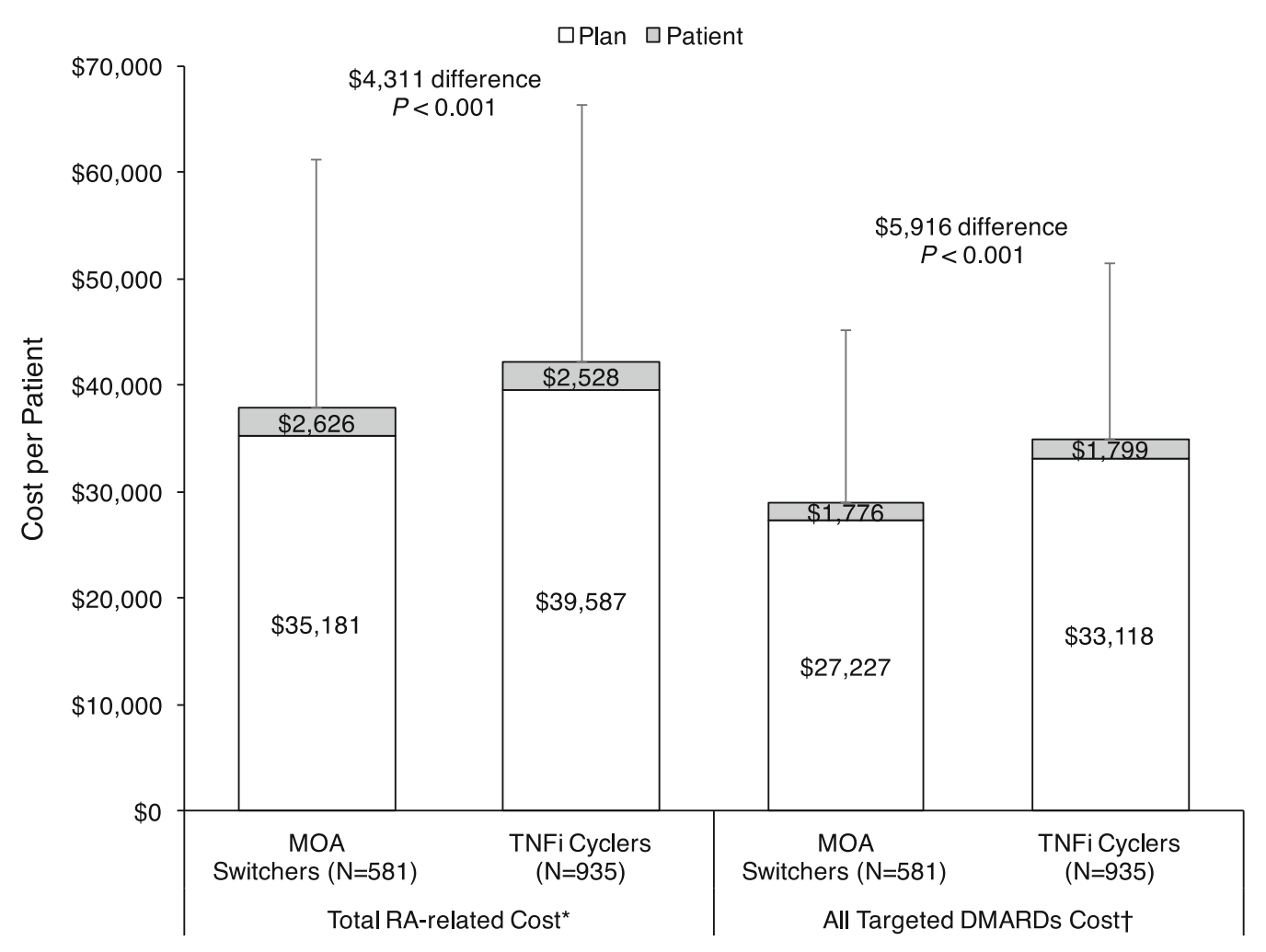

(B) Estimated cost per persistent patient over 1-year follow-up period

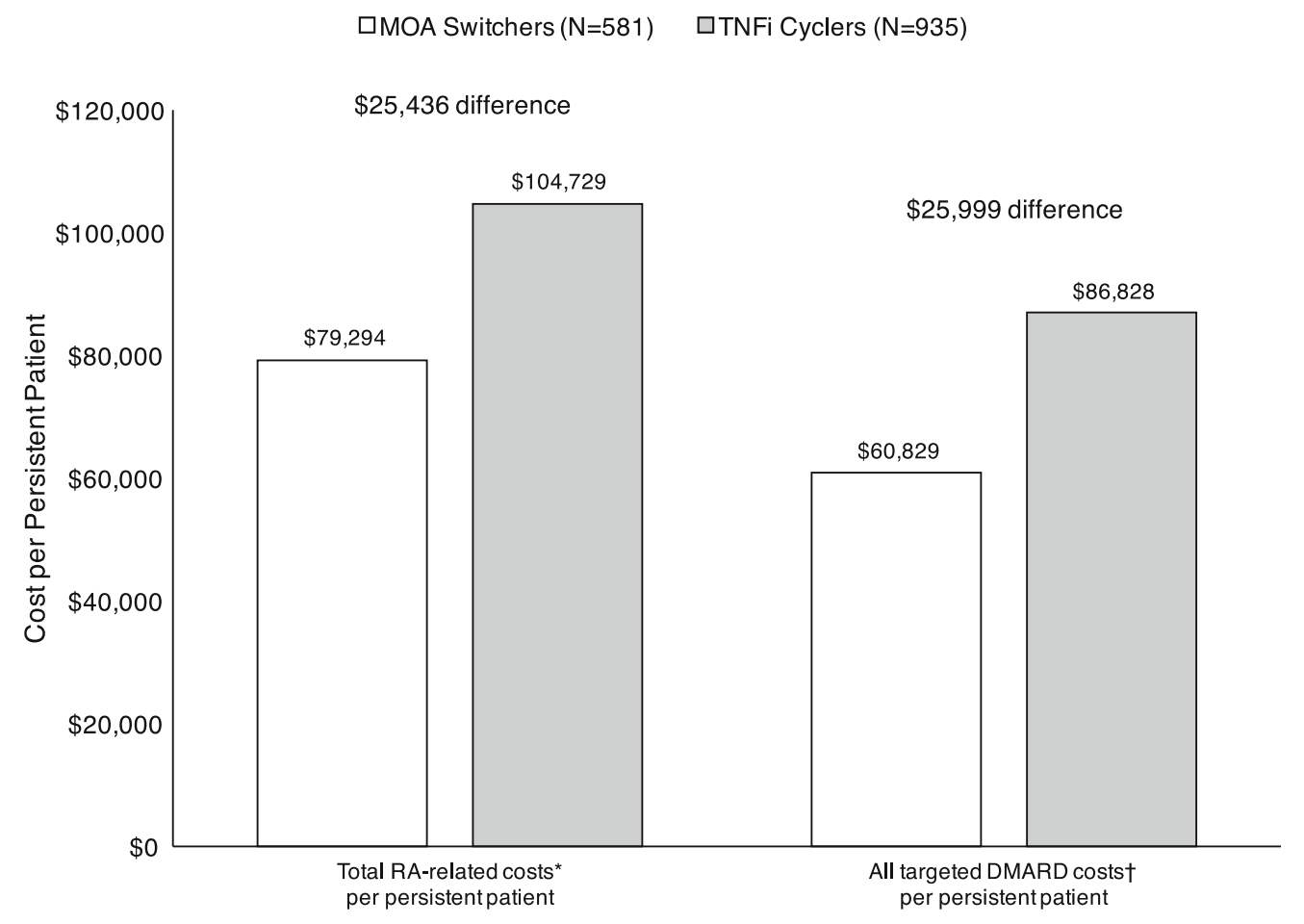


4Fig. 3 One-year cost per patient and per persistent patient. Asterisk total RA-related cost includes amount paid for diagnosis and treatment related to RA. Dagger all targeted DMARDs cost includes cost for both the index therapy and any other targeted DMARD in the first year post-index. DMARD disease-modifying antirheumatic drug, $M O A$ mechanism of action, $R A$ rheumatoid arthritis, $S D$ standard deviation, $T N F i$ tumor necrosis factor inhibitor. a Mean (SD) costs per patient in 1-year follow-up period. b Estimated cost per persistent patient over 1-year follow-up period

cyclers and were more likely to be persistent on treatment at 1 year. Other analyses reported similar findings, with better treatment persistence rates among MOA switchers compared with TNFi cyclers [7-10], but those studies did not examine the cost per persistent patient. Consistent findings for treatment persistence across different patient populations may have clinical implications for the management of RA, because greater treatment persistence and adherence have been reported to improve clinical outcomes in RA [22]. This analysis was not designed to examine treatment effectiveness, but several previous retrospective analyses, registry studies, and prospective clinical studies have reported greater treatment effectiveness after MOA switching compared with TNFi cycling [8, 9, 11, 16, 20, 25-28].

Based in part on the emerging evidence, recent updates to RA treatment guidelines placed increased emphasis on the use of different MOA therapies [5, 6]. Because these guidelines were updated after the study period for our analysis, additional research is needed to determine whether the recent changes to the treatment guidelines will influence clinical practice and lead to increased use of different MOA therapies compared with TNFi.

This analysis also examined the healthcare costs paid by the plan and the patient after switching to a different MOA or cycling to another TNFi. The mean cost was significantly lower among the MOA switchers than the TNFi cyclers, both for the total cost of care for RA, as well as for the total cost of the targeted DMARDs in the first year after the change in therapy. In multivariable analyses that included baseline patient characteristics, the costs continued to be significantly lower among the MOA switchers. Previous research has reported that persistent patients have higher costs for TNFi therapy compared with non-persistent patients, but lower non-drug costs [29]. The results of our study indicate that switching to a different MOA may lower not only the nondrug healthcare costs but also the drug costs compared with TNFi cycling because the observed difference in mean RA-related costs was driven largely by lower targeted DMARD costs among MOA switchers versus TNFi cyclers. Thus, MOA switchers were persistent on therapy for longer, yet they had lower targeted DMARD costs. In this analysis, targeted DMARD costs included not only those for the index targeted DMARD but also those for other targeted DMARDs when patients changed therapy again post-index. TNFi cyclers were significantly more likely than MOA switchers to change therapy again post-index. After these subsequent changes in therapy, the need for more costly loading doses for the new therapy may have contributed to the observed difference in the total cost of targeted DMARDs.

The final step in this analysis was to examine the cost per persistent patient in each cohort. When the costs and treatment persistence rates were combined, MOA switchers had lower cost per persistent patient than TNFi cyclers. These findings, combined with previous evidence that MOA switching simultaneously lowers costs and improves clinical outcomes compared with TNFi cycling [9], suggest that MOA switching is associated with economic and clinical advantages for RA patients and their health plans when a change in therapy is required.

Because this was a retrospective analysis of claims data, the patient populations were not stratified or balanced before the change in therapy, so multivariable analyses were used to adjust for differences at baseline. Other statistically significant predictors of non-persistence in the multivariable analysis included comorbidity index score and total healthcare expenditure before the change in therapy, which suggests that patients with more severe disease were less likely to persist on therapy after cycling TNFi or switching to a different MOA. Greater pre-index 
Table 3 Multivariable analysis of predictors for 1-year RA-related costs

\begin{tabular}{|c|c|c|c|c|c|}
\hline & $\begin{array}{l}\text { Cost } \\
\text { ratio }\end{array}$ & Lower 95\% CI & Upper 95\% CI & $P$ value & $\begin{array}{l}\text { Predicted } \\
\text { value }\end{array}$ \\
\hline \multicolumn{6}{|l|}{ Patient cohort (ref $=$ TNFi cyclers) } \\
\hline MOA switchers & 0.888 & 0.838 & 0.941 & $<0.001$ & $\$ 37,557$ \\
\hline TNFi cyclers & Ref. & - & - & - & $\$ 42,280$ \\
\hline \multicolumn{6}{|l|}{ Age group $($ ref $=65+)$} \\
\hline $18-44$ & 1.020 & 0.911 & 1.141 & 0.732 & - \\
\hline $45-64$ & 1.120 & 1.015 & 1.236 & 0.024 & - \\
\hline Male (ref $=$ female) & 1.062 & 0.990 & 1.140 & 0.094 & - \\
\hline \multicolumn{6}{|l|}{ Insurance plan type $($ ref $=$ commercial $)$} \\
\hline Medicare & 0.935 & 0.854 & 1.025 & 0.151 & - \\
\hline \multicolumn{6}{|l|}{ Index year $($ ref $=2012)$} \\
\hline 2013 & 1.026 & 0.957 & 1.100 & 0.473 & - \\
\hline 2014 & 0.976 & 0.876 & 1.087 & 0.657 & - \\
\hline \multicolumn{6}{|l|}{ Region (ref = South) } \\
\hline Northeast & 1.082 & 0.973 & 1.204 & 0.147 & - \\
\hline Midwest & 1.048 & 0.980 & 1.120 & 0.169 & - \\
\hline West & 1.089 & 1.005 & 1.179 & 0.038 & - \\
\hline Charlson comorbidity index & 0.997 & 0.962 & 1.033 & 0.863 & - \\
\hline Hydroxychloroquine pre-index & 0.974 & 0.907 & 1.045 & 0.465 & - \\
\hline Leflunomide pre-index & 0.971 & 0.892 & 1.057 & 0.497 & - \\
\hline Methotrexate pre-index & 1.036 & 0.978 & 1.097 & 0.225 & - \\
\hline Sulfasalazine pre-index & 1.028 & 0.925 & 1.143 & 0.609 & - \\
\hline Count of unique RA medications pre-index & 0.997 & 0.959 & 1.037 & 0.897 & - \\
\hline Total expenditure pre-index $/ \$ 1000$ & 1.004 & 1.001 & 1.007 & 0.015 & - \\
\hline RA-related total expenditure pre-index $/ \$ 1000$ & 1.003 & 0.999 & 1.006 & 0.144 & - \\
\hline Office visit count pre-index & 1.008 & 1.004 & 1.012 & $<0.001$ & - \\
\hline
\end{tabular}

$M O A$ mechanism of action, $R A$ rheumatoid arthritis, ref reference, $T N F i$ tumor necrosis factor inhibitor

expenditures and greater pre-index office visits also predicted higher costs after a change in therapy.

Several potential limitations of the analysis are noted. A claims data study does not provide the reasons for discontinuation of therapy, which could be as a result of adverse events, lack of efficacy, cost burden, or even clinical remission. In future research, it would be useful to combine the findings from this study with additional context around why patients discontinue both the prior TNFi and the new therapy after TNFi cycling or MOA switching, including possible patient-specific psychological determinants of persistence. Another area for future research is to examine treatment 
Table 4 Multivariable analysis of predictors for 1-year targeted DMARD costs

\begin{tabular}{|c|c|c|c|c|c|}
\hline & Cost ratio & Lower 95\% CI & Upper 95\% CI & $P$ value & Predicted value \\
\hline \multicolumn{6}{|l|}{ Patient cohort (ref $=$ TNFi cyclers $)$} \\
\hline MOA switchers & 0.837 & 0.793 & 0.883 & $<0.001$ & $\$ 29,146$ \\
\hline TNFi cyclers & Ref. & - & - & - & $\$ 34,831$ \\
\hline \multicolumn{6}{|l|}{ Age group $(\mathrm{ref}=65+)$} \\
\hline $18-44$ & 1.092 & 0.985 & 1.211 & 0.095 & - \\
\hline $45-64$ & 1.143 & 1.044 & 1.252 & 0.004 & - \\
\hline Male $(\mathrm{ref}=$ female $)$ & 1.012 & 0.948 & 1.081 & 0.723 & - \\
\hline \multicolumn{6}{|l|}{ Insurance plan type $(\mathrm{ref}=$ commercial $)$} \\
\hline Medicare & 0.944 & 0.868 & 1.028 & 0.185 & - \\
\hline \multicolumn{6}{|l|}{ Index year $(\mathrm{ref}=2012)$} \\
\hline 2013 & 1.041 & 0.976 & 1.111 & 0.225 & - \\
\hline 2014 & 1.040 & 0.940 & 1.150 & 0.450 & - \\
\hline \multicolumn{6}{|l|}{ Region (ref = South) } \\
\hline Northeast & 1.026 & 0.929 & 1.133 & 0.617 & - \\
\hline Midwest & 0.951 & 0.894 & 1.012 & 0.112 & - \\
\hline West & 1.015 & 0.942 & 1.093 & 0.702 & - \\
\hline Charlson comorbidity index & 0.994 & 0.961 & 1.027 & 0.702 & - \\
\hline Hydroxychloroquine pre-index & 0.993 & 0.930 & 1.060 & 0.827 & - \\
\hline Leflunomide pre-index & 1.007 & 0.930 & 1.090 & 0.858 & - \\
\hline Methotrexate pre-index & 1.053 & 0.998 & 1.111 & 0.058 & - \\
\hline Sulfasalazine pre-index & 1.005 & 0.910 & 1.110 & 0.926 & - \\
\hline Count of unique RA medications pre-index & 0.957 & 0.922 & 0.992 & 0.018 & - \\
\hline Total expenditure pre-index $/ \$ 1000$ & 0.993 & 0.990 & 0.996 & $<0.001$ & - \\
\hline RA-related total expenditure pre-index $/ \$ 1000$ & 1.011 & 1.008 & 1.015 & $<0.001$ & - \\
\hline Office visit count pre-index & 1.002 & 0.998 & 1.006 & 0.290 & - \\
\hline
\end{tabular}

$D M A R D$ disease-modifying antirheumatic drug, $M O A$ mechanism of action, $R A$ rheumatoid arthritis, $r e f$ reference, $T N F i$ tumor necrosis factor inhibitor

persistence for intravenous versus subcutaneous therapies. Claims data are collected for payment and not for research, and they do not include clinical outcomes such as disease severity. We could not control for RA disease activity at the time of biologic initiation and patients were not randomized to treatment with a TNFi or different MOA DMARD, so causality cannot be inferred from the results. Drug costs in claims do not include the effect of confidential discounts or rebates. Because the first TNFi claim in the study period was not necessarily the patient's first lifetime use of a TNFi, it was possible that patients had an unobserved history of 
other targeted DMARD therapy before the study period. Other MOA DMARDs that were not available during the study period, such as sarilumab [30, 31], sirukumab [32], or baricitinib [33], may change which biologics are used in the management of RA.

This study did not examine outcomes separately for individual medications within each class. Previous analyses of TNFi cycling or switching to a different MOA after TNFi failure compared either switching to a single non-TNFi versus TNFi cycling [16, 20, 25-28] or broadly compared switching to any non-TNFi versus TNFi cycling $[8,9,11]$. This approach is supported by studies in the frontline treatment setting, which have shown that response rates generally are similar among TNFi and other MOA [34]. However, randomized studies have shown that response to monotherapy with an antibody to IL-6 such as tocilizumab or sarilumab is greater than the response to monotherapy with a TNFi when methotrexate treatment fails [31, 35]. The relevance of these results to second-line therapy after TNFi failure remains to be determined.

\section{CONCLUSIONS}

After changing TNFi therapy, RA patients who switched to a different MOA had higher treatment persistence and lower healthcare costs than TNFi cyclers, resulting in lower healthcare costs per persistent patient among the MOA switchers. The health plan was responsible for most of the cost of care for these patients. Reimbursement policies that require patients to cycle TNFi before they switch to a different MOA may result in suboptimal outcomes for both patients and payers.

\section{ACKNOWLEDGEMENTS}

Sanofi (Bridgewater, NJ) and Regeneron Pharmaceuticals (Tarrytown, NJ) funded this work and the article processing charges. All authors had full access to all of the data in this study and take complete responsibility for the integrity of the data and accuracy of the data analysis.

All named authors meet the International Committee of Medical Journal Editors (ICMJE) criteria for authorship for this manuscript, take responsibility for the integrity of the work as a whole, and have given final approval for the version to be published.

Medical Writing, Editorial, and Other Assistance. Jonathan Latham of PharmaScribe, LLC assisted with the preparation of the manuscript and Prime assisted with the submission of the manuscript; both were supported by Sanofi and Regeneron Pharmaceuticals.

Disclosures. Benjamin Chastek is an employee of Optum, which received research support from Sanofi and Regeneron Pharmaceuticals. Chieh-I Chen is an employee and stockholder of Regeneron Pharmaceuticals. Andreas Kuznik is an employee and stockholder of Regeneron Pharmaceuticals. Wenhui Wei is an employee of Regeneron Pharmaceuticals and a stockholder of Sanofi. Clare Proudfoot is a former employee and current stockholder of Sanofi. Shraddha Shinde is a former employee and current stockholder of Sanofi.

Compliance with Ethics Guidelines. All records were de-identified and no identifiable protected health information was extracted or accessed during the study, pursuant to the US Health Insurance Portability and Accountability Act. Because the study did not involve the collection, use, or transmittal of individually identifiable data, and data were collected in the setting for the usual care of the patient, institutional review board approval to conduct this study was not necessary.

Data Availability. The datasets generated during and/or analyzed during the current study are available from the corresponding author on reasonable request.

Open Access. This article is distributed under the terms of the Creative Commons Attribution-NonCommercial 4.0 International 
License (http://creativecommons.org/licenses/ by-nc/4.0/), which permits any noncommercial use, distribution, and reproduction in any medium, provided you give appropriate credit to the original author(s) and the source, provide a link to the Creative Commons license, and indicate if changes were made.

\section{REFERENCES}

1. Aletaha D, Neogi T, Silman AJ, et al. 2010 Rheumatoid arthritis classification criteria: an American College of Rheumatology/European League Against Rheumatism collaborative initiative. Arthritis Rheum. 2010;62(9):2569-81.

2. Saag KG, Teng GG, Patkar NM, et al. American College of Rheumatology 2008 recommendations for the use of nonbiologic and biologic disease-modifying antirheumatic drugs in rheumatoid arthritis. Arthritis Rheum. 2008;59(6):762-84.

3. Singh JA, Furst DE, Bharat A, et al. 2012 update of the 2008 American College of Rheumatology recommendations for the use of disease-modifying antirheumatic drugs and biologic agents in the treatment of rheumatoid arthritis. Arthritis Care Res (Hoboken). 2012;64(5):625-39.

4. Smolen JS, Landewé R, Breedveld FC, et al. EULAR recommendations for the management of rheumatoid arthritis with synthetic and biological disease-modifying antirheumatic drugs: 2013 update. Ann Rheum Dis. 2014;73(3):492-509.

5. Smolen JS, Landewe R, Bijlsma J, et al. EULAR recommendations for the management of rheumatoid arthritis with synthetic and biological disease-modifying antirheumatic drugs: 2016 update. Ann Rheum Dis. 2017;76(6):960-77.

6. Singh JA, Saag KG, Bridges SL Jr, et al. 2015 American College of Rheumatology guideline for the treatment of rheumatoid arthritis. Arthritis Rheumatol. 2016;68(1):1-26.

7. Baser O, Ganguli A, Roy S, Xie L, Cifaldi M. Impact of switching from an initial tumor necrosis factor inhibitor on health care resource utilization and costs among patients with rheumatoid arthritis. Clin Ther. 2015;37(7):1454-65.

8. Bonafede MM, Curtis JR, McMorrow D, Mahajan P, Chen CI. Treatment effectiveness and treatment patterns among rheumatoid arthritis patients after switching from a tumor necrosis factor inhibitor to another medication. Clinicoecon Outcomes Res. 2016;8:707-15.

9. Chastek B, Becker LK, Chen CI, Mahajan P, Curtis JR. Outcomes of tumor necrosis factor inhibitor cycling versus switching to a disease-modifying anti-rheumatic drug with a new mechanism of action among patients with rheumatoid arthritis. J Med Econ. 2017;20(5):464-73.

10. Rotar Z, Hočevar A, Rebolj Kodre A, Praprotnik S, Tomšič M. Retention of the second-line biologic disease-modifying antirheumatic drugs in patients with rheumatoid arthritis failing one tumor necrosis factor alpha inhibitor: data from the BioRx.si registry. Clin Rheumatol. 2015;34(10):1787-93.

11. Gottenberg JE, Brocq $\mathrm{O}$, Perdriger $\mathrm{A}$, et al. Non-TNF-targeted biologic vs a second anti-TNF drug to treat rheumatoid arthritis in patients with insufficient response to a first anti-TNF drug: a randomized clinical trial. JAMA. 2016;316(11):1172-80.

12. Institute for Clinical and Economic Review. Targeted immune modulators for rheumatoid arthritis: effectiveness \& value. https://icer-review.org/ material/ra-final-report/. Boston: ICER; 2017. Accessed 27 Apr 2017.

13. Bonafede M, Fox KM, Watson C, Princic N, Gandra SR. Treatment patterns in the first year after initiating tumor necrosis factor blockers in real-world settings. Adv Ther. 2012;29(8):664-74.

14. Harnett J, Wiederkehr D, Gerber R, Gruben D, Koenig A, Bourret J. Real-world evaluation of TNF-inhibitor utilization in rheumatoid arthritis. J Med Econ. 2016;19(2):91-102.

15. Kamal KM, Madhavan SS, Hornsby JA, Miller LA, Kavookjian J, Scott V. Use of tumor necrosis factor inhibitors in rheumatoid arthritis: a national survey of practicing United States rheumatologists. Joint Bone Spine. 2006;73(6):718-24.

16. Finckh A, Ciurea A, Brulhart L, et al. Which subgroup of patients with rheumatoid arthritis benefits from switching to rituximab versus alternative anti-tumour necrosis factor (TNF) agents after previous failure of an anti-TNF agent? Ann Rheum Dis. 2010;69(2):387-93.

17. Reynolds A, Koenig AS, Bananis E, Singh A. When is switching warranted among biologic therapies in rheumatoid arthritis? Expert Rev Pharmacoecon Outcomes Res. 2012;12(3):319-33.

18. Favalli EG, Biggioggero M, Marchesoni A, Meroni PL. Survival on treatment with second-line biologic therapy: a cohort study comparing cycling and 
swap strategies. Rheumatology (Oxford). 2014;53(9):1664-8.

19. Bergman MJ, Elkin EP, Ogale S, Kamath T, Hamburger MI. Response to biologic disease-modifying anti-rheumatic drugs after discontinuation of anti-tumor necrosis factor alpha agents for rheumatoid arthritis. Rheumatol Ther. 2014;1(1):21-30.

20. Chatzidionysiou K, van Vollenhoven RF. Rituximab versus anti-TNF in patients who previously failed one TNF inhibitor in an observational cohort. Scand J Rheumatol. 2013;42(3):190-5.

21. United Healthcare Online. Tools and Resources $>$ Pharmacy Resources $>$ Clinical Programs $>$ Step Therapy. $\quad$ https://www. unitedhealthcareonline.com/. Accessed 27 Apr 2017.

22. Curtis JR, Bykerk VP, Aassi M, Schiff M. Adherence and persistence with methotrexate in rheumatoid arthritis: a systematic review. J Rheumatol. 2016;43(11):1997-2009.

23. Charlson ME, Pompei P, Ales KL, MacKenzie CR. A new method of classifying prognostic comorbidity in longitudinal studies: development and validation. J Chronic Dis. 1987;40(5):373-83.

24. Deyo RA, Cherkin DC, Ciol MA. Adapting a clinical comorbidity index for use with ICD-9-CM administrative databases. J Clin Epidemiol. 1992;45(6):613-9.

25. Soliman MM, Hyrich KL, Lunt $M$, Watson $\mathrm{KD}$, Symmons DP, Ashcroft DM. Rituximab or a second anti-tumor necrosis factor therapy for rheumatoid arthritis patients who have failed their first anti-tumor necrosis factor therapy? Comparative analysis from the British Society for Rheumatology Biologics Register. Arthritis Care Res (Hoboken). 2012;64(8):1108-15.

26. Harrold LR, Reed GW, Magner R, et al. Comparative effectiveness and safety of rituximab versus subsequent anti-tumor necrosis factor therapy in patients with rheumatoid arthritis with prior exposure to anti-tumor necrosis factor therapies in the United States Corrona registry. Arthritis Res Ther. $2015 ; 17: 256$.

27. Kekow J, Mueller-Ladner U, Schulze-Koops $H$. Rituximab is more effective than second anti-TNF therapy in rheumatoid arthritis patients and previous TNFalpha blocker failure. Biologics. 2012;6:191-9.

28. Gomez-Reino JJ, Maneiro JR, Ruiz J, Rosello R, Sanmarti R, Romero AB. Comparative effectiveness of switching to alternative tumour necrosis factor (TNF) antagonists versus switching to rituximab in patients with rheumatoid arthritis who failed previous TNF antagonists: the MIRAR Study. Ann Rheum Dis. 2012;71(11):1861-4.

29. Tang B, Rahman M, Waters HC, Callegari P. Treatment persistence with adalimumab, etanercept, or infliximab in combination with methotrexate and the effects on health care costs in patients with rheumatoid arthritis. Clin Ther. 2008;30(7):1375-84.

30. Genovese MC, Fleischmann R, Kivitz AJ, et al. Sarilumab plus methotrexate in patients with active rheumatoid arthritis and inadequate response to methotrexate: results of a phase III study. Arthritis Rheumatol. 2015;67(6):1424-37.

31. Burmester GR, Lin Y, Patel R, et al. Efficacy and safety of sarilumab monotherapy versus adalimumab monotherapy for the treatment of patients with active rheumatoid arthritis (MONARCH): a randomised, double-blind, parallel-group phase III trial. Ann Rheum Dis. 2017;76(5):840-7.

32. Aletaha D, Bingham CO 3rd, Tanaka Y, et al. Efficacy and safety of sirukumab in patients with active rheumatoid arthritis refractory to anti-TNF therapy (SIRROUND-T): a randomised, double-blind, placebo-controlled, parallel-group, multinational, phase 3 study. Lancet. 2017;389(10075):1206-17.

33. Genovese MC, Kremer J, Zamani O, et al. Baricitinib in patients with refractory rheumatoid arthritis. N Engl J Med. 2016;374(13):1243-52.

34. Singh JA, Hossain A, Tanjong Ghogomu E, et al. Biologics or tofacitinib for rheumatoid arthritis in incomplete responders to methotrexate or other traditional disease-modifying anti-rheumatic drugs: a systematic review and network meta-analysis. Cochrane Database Syst Rev. 2016;5:CD012183.

35. Gabay C, Emery P, van Vollenhoven R, et al. Tocilizumab monotherapy versus adalimumab monotherapy for treatment of rheumatoid arthritis (ADACTA): a randomised, double-blind, controlled phase 4 trial. Lancet. 2013;381(9877):1541-50. 